Article

\title{
Climatic Niche Shift during Azolla filiculoides Invasion and Its Potential Distribution under Future Scenarios
}

\author{
Argantonio Rodríguez-Merino ${ }^{1, *(\mathbb{D})}$, Rocío Fernández-Zamudio ${ }^{2}$, Pablo García-Murillo ${ }^{1}$ (D) \\ and Jesús Muñoz ${ }^{3}$ (D) \\ 1 Department of Plant Biology and Ecology, Faculty of Pharmacy, University of Seville, Profesor García \\ González 2, 41012 Seville, Spain; pgarcia@us.es \\ 2 Doñana Biological Station (EBD-CSIC), Avda. Américo Vespucio s/n, 41092 Seville, Spain; \\ rzamudio@ebd.csic.es \\ 3 Real Jardín Botánico (RJB-CSIC), Plaza de Murillo 2, 28014 Madrid, Spain; jmunoz@rjb.csic.es \\ * Correspondence: argantonio.rodriguez@gmail.com
}

Received: 29 September 2019; Accepted: 16 October 2019; Published: 18 October 2019

check for updates

\begin{abstract}
In order to prevent future biological invasions, it is crucial to know non-native species distributions. We evaluated the potential global distribution of Azolla filiculoides, a free-floating macrophyte native to the Americas by using species distribution models and niche equivalency tests to analyze the degree of niche overlap between the native and invaded ranges of the species. The models were projected under two future emission scenarios, three global circulation models and two time periods. Our results indicate a possible niche shift between the distribution ranges of the species, indicating that $A$. filiculoides can adapt to novel environmental conditions derived from climatic differences during the invasion process. Our models also show that the future potential distribution of $A$. filiculoides will decrease globally, although the species could colonize new vulnerable regions where it is currently absent. We highlight that species occurrence records in the invaded area are necessary to generate accurate models, which will, in turn, improve our ability to predict potential invasion risk areas.
\end{abstract}

Keywords: aquatic plants; climate change; invasive species; MaxEnt; niche overlap; species distribution models

\section{Introduction}

Biological invasions and climate change are among the top five major drivers of biodiversity loss in freshwater ecosystems, along with land-use change, nitrogen deposition, and elevated carbon dioxide concentrations [1,2]. The effects of climate change can dramatically influence the distribution of aquatic species, including non-native ones [3,4]. Knowing the potential distribution of invasive species would be decisive not only for minimizing damage associated with accidental introductions, but also for the development of early detection programs and strategies in susceptible areas [5-7]. In addition, in order to understand the future potential distribution of these species under the effects of projected climate scenarios, it is crucial to identify current species dynamics, which can be the basis for implementing appropriate management actions to reduce negative consequences on natural habitats and biodiversity [3].

The invasion process is more successful when species colonize climatic environments similar to those of its native range [8]. The niche conservatism principle (niches are conserved through space and time) is, therefore, often considered in analyses of non-native species potential distribution. Under this principle, niche models are calibrated on the native distribution area and projected onto the invaded 
one to assess invasion risk [8,9]. However, there are many factors that influence the invasion process, such as propagule pressure, geographic and/or climatic barriers, human activities, competition between organisms, as well as many other factors that can result in species niche divergence [10,11]. Analyses of the potential distribution of species that ignore non-native species occurrences in non-native regions could produce uncertainties, as all of the environmental variability acquired by the studied species in novel colonized habitats would not be taken into account [11,12].

In recent years, species distribution models (SDMs) have become more frequently used in the management and control of non-native species [13-15]. SDM techniques allow correlating species occurrence records with environmental variables to uncover the potential distribution of a species and, thus, to find the most suitable areas for the species survival [14,16]. For this reason, SDMs have been used in some studies to analyze whether there is niche conservatism or niche shift between native and invaded distribution ranges, the results of which were used to design appropriate management strategies [11,12].

Aquatic invasive plants are considered among the most damaging invaders in freshwater ecosystems as they can alter the structure and composition of habitats, and the biogeochemistry and water quality of the systems they invade [17]. Principal characteristics that allow aquatic plants to be potential invaders include phenotypic plasticity and their ability to tolerate a wide range of environmental conditions and to adapt to disturbed systems $[15,18]$. Changes in species physiology due to phenotypic plasticity together with propagule pressure, favored mainly by human activities, can lead to the use of different niches by non-native aquatic plants $[9,19]$. These characteristics make aquatic plants excellent model organisms to study environmental niche changes.

Our study focuses on Azolla filiculoides Lamarck 1783 (Salviniaceae), a small heterosporous free-floating fern native to the American continent [20] that is now distributed worldwide (Figure 1) and is considered an aquatic invasive species (AIS) in some geographic areas [21]. Azolla filiculoides has a very high growth rate, even under suboptimal conditions, and it can form dense mats that block light, leading to the impoverishment or even disappearance of submerged plants and associated communities [22,23]. In addition, this species forms a symbiosis with a nitrogen-fixing cyanobacteria to obtain atmospheric nitrogen $[24,25]$, and its potential for vegetative reproduction in the absence of adequate conditions is very high [26]. Given these features, A. filiculoides is one of the most dangerous invaders affecting freshwater habitats and their biodiversity [27-30].

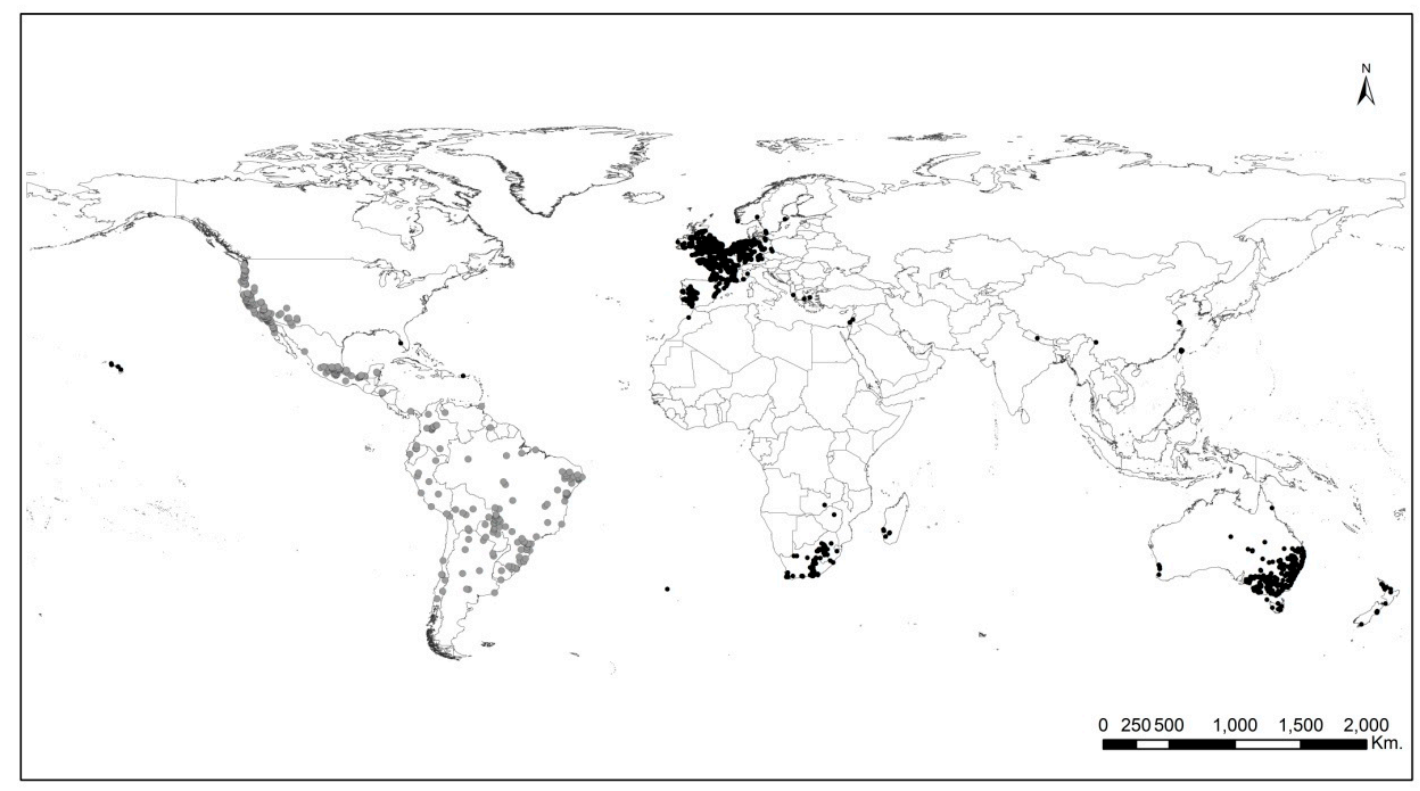

Figure 1. Global geographic distribution of Azolla filiculoides. Grey dots represent native occurrence localities and black dots represent invaded occurrence localities. 
Here, we used SDMs to investigate a possible niche shift during the A. filiculoides invasion process. We also used two metrics of niche overlap and multivariate techniques to further support the SDM results $[12,31,32]$. Our main aims were to (1) examine whether the climatic niche of $A$. filiculoides is uniform between native and invaded ranges, (2) characterize the climatic tolerances of $A$. filiculoides in both native and invaded ranges and (3) describe the future potential distribution of $A$. filiculoides at the global scale.

\section{Results}

\subsection{Niche Overlap in Environmental Space}

The native and invasive distributions of $A$. filiculoides are clearly separated in multidimensional environmental space (Figure 2A). The first two Principal Component Analysis (PCA) axes explained 79.8\% of the variation in the data (PCA1: $48.8 \%$ and PCA2: 31\%). The first PCA axis was positively related to temperature seasonality (Bio 4) and precipitation of the driest quarter (Bio 17), whereas the second PCA axis was negatively related to minimum temperature of the coldest month (Bio 6), annual precipitation (Bio 12), precipitation of the wettest quarter (Bio 16) and Bio 17 (Figure 2B). The non-native occurrence records occupied drier areas with higher pronounced seasonality. There are some climatic coincidences in the distribution ranges, although the invaded range shows new climatic areas unknown in the species' native distribution range (Figure 2A).
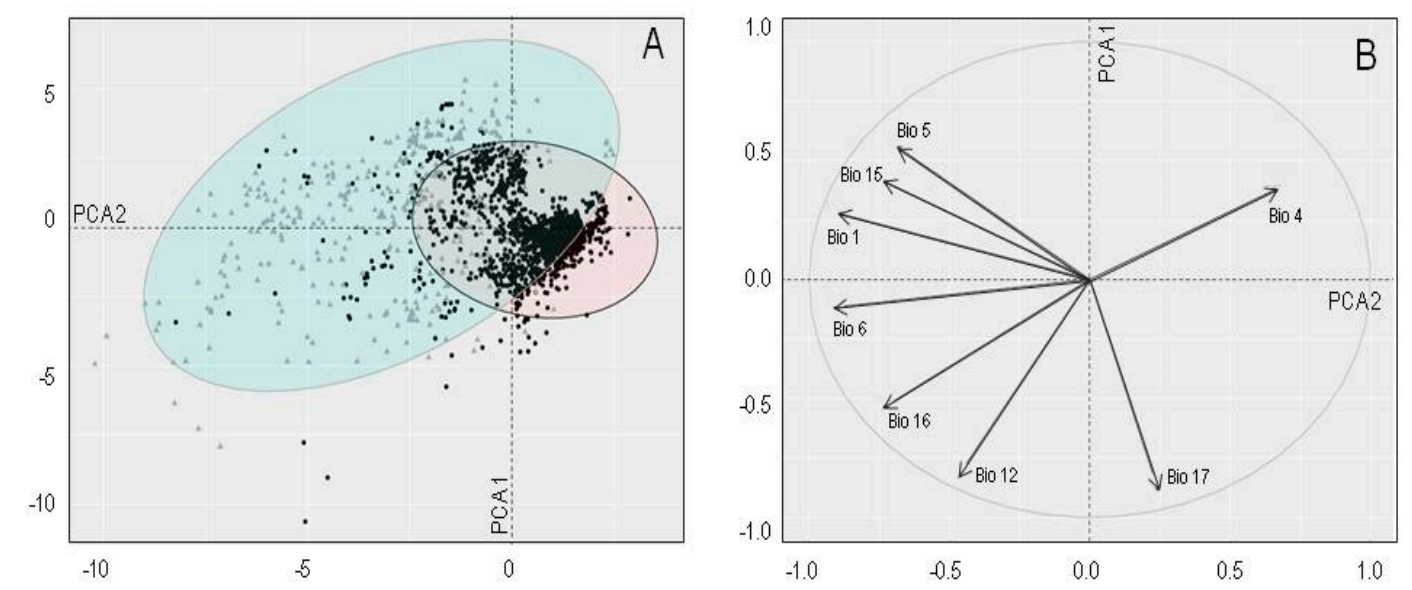

Figure 2. (A) The principal component analysis (PCA) for two Azolla filiculoides ranges. Grey triangles represent native localities and black dots represent invasive localities in the environmental space. Ellipse level 0.95. (B) Bioclimatic variables in the environmental space defined by the first two principal component axes. PCA1 and PCA2 explained $48.8 \%$ and $31 \%$ of the variation in the data, respectively. Annual mean temperature (Bio 1), temperature seasonality (Bio 4), maximum temperature of the warmest month (Bio 5), minimum temperature of the coldest month (Bio 6), annual precipitation (Bio 12), precipitation seasonality (Bio 15), precipitation of the wettest quarter (Bio 16), and precipitation of the driest quarter (Bio 17).

\subsection{Species Distribution Modeling}

The high area under the receiver operating characteristic (ROC) curve AUC values indicated highly accurate performance for all models (Table 1). The native model (trained on the native area) reflected the current distribution of A. filiculoides in the Americas (Figure 3A). However, when the native model was projected onto the invaded area, the predicted potential distribution was broader than the known distribution of the species (Figure 3B). In contrast, the invasive model (trained on the invaded area) underestimated the suitable area of A. filiculoides on the native region (Figure 3C), though it correctly showed the distribution of the species on the invaded range (Figure 3D). Figure 4 
shows a suitability map for A. filiculoides under current climatic conditions using native and invaded range occurrences.

Table 1. The table shows the number of occurrence records $(\mathrm{N})$ was used for building the different models and the AUC values and standard deviation for Azolla filiculoides models performance.

\begin{tabular}{cccc}
\hline & Native Model & Invasive Model & Global Model \\
\hline N (occurrence records) & 331 & 1882 & 2213 \\
AUC \pm SD & $0.907 \pm 0.023$ & $0.916 \pm 0.004$ & $0.895 \pm 0.006$ \\
\hline
\end{tabular}
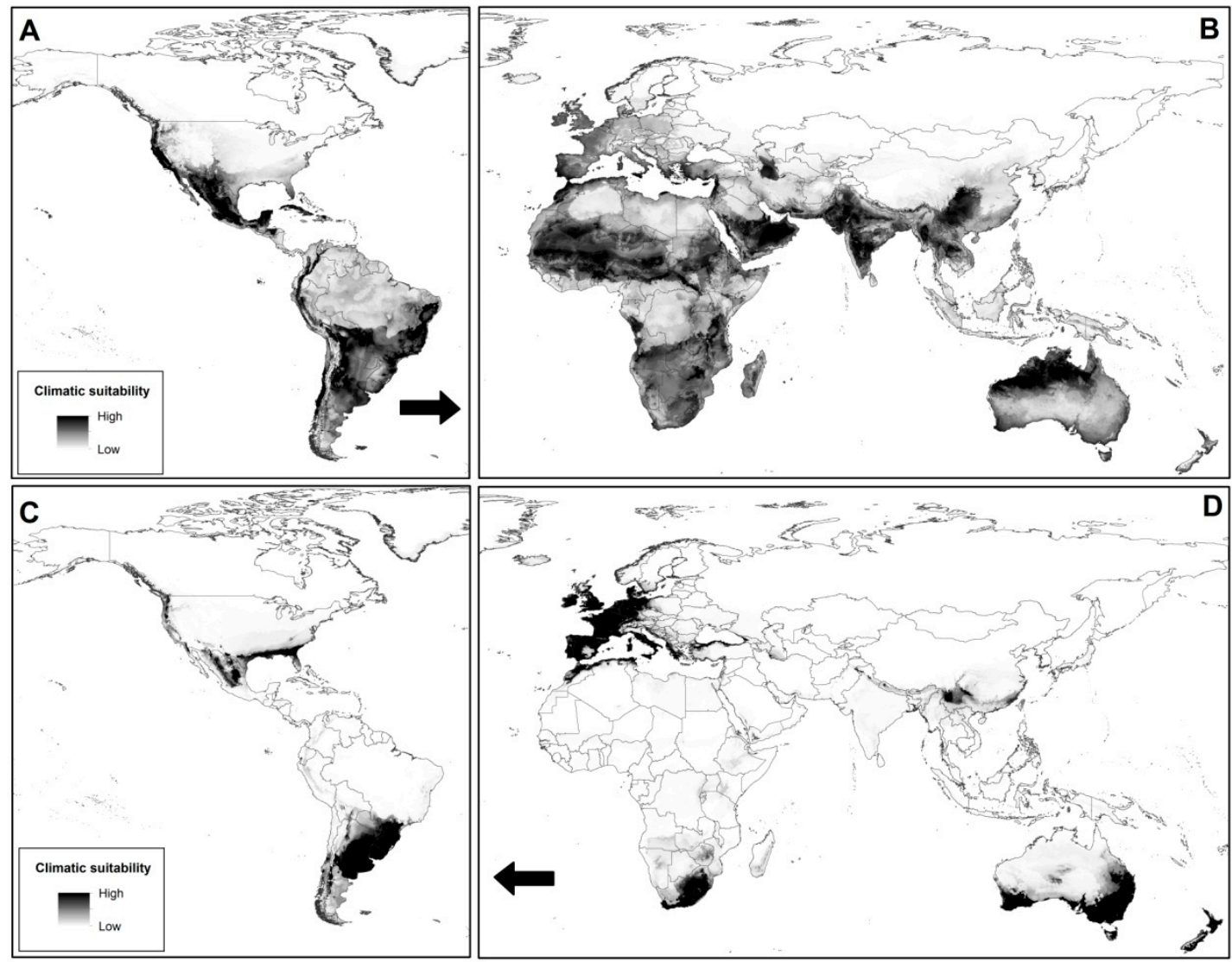

Figure 3. Current potential distribution of Azolla filiculoides based on reciprocal models. (A) Model calibrated with native occurrences and (B) model projected onto the invasive range. (C) Model projected onto the native range and (D) model calibrated with invasive occurrences. Darker shades indicate higher environmental suitability. Arrows indicate the direction of model projections. 


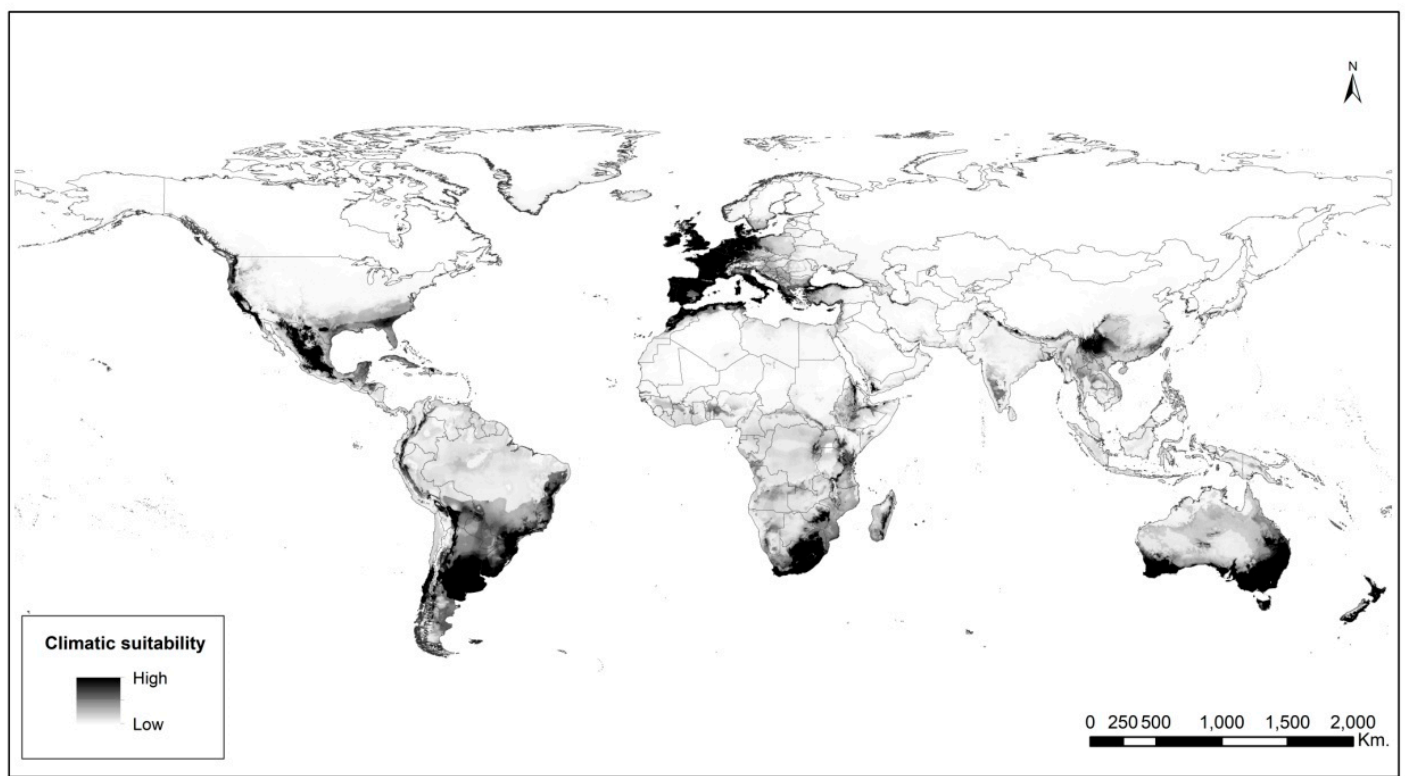

Figure 4. Current distribution and climate suitability model of Azolla filiculoides based on presence occurrences from both invaded and native ranges. Darker shades indicate higher environmental suitability.

\subsection{Niche Overlap Analyses}

The results of the identity test allowed us to reject the null hypothesis of niche identity, since Schoener's D (0.401) and Hellinger's I statistics (0.703) were lower than expected by chance (Figure S1, Supplementary Materials). The background similarity test results proved that niche similarity was greater than expected by chance in both directions, i.e., from native to invaded range and from invaded to native range ( $D: 0.405$ and I: 0.705; Figure S2).

\subsection{Predicted Niche Occupancy}

Predicted niche occupancy (PNO) profiles indicated differences in the climatic requirements of $A$. filiculoides in native versus invaded ranges (Figure 5). The potential distribution of $A$. filiculoides in the invaded range showed greater suitability in colder areas (Figure 5A,C,D), with more pronounced temperature seasonality (Figure 5B), lower precipitation seasonality (Figure 5F) and drier summers (Figure $5 \mathrm{H}$ ). On the contrary, the potential distribution in the native range noted greater suitability in warmer environments (Figure 5A,C,D) that have lower temperature seasonality (Figure 5B), and higher and more pronounced seasonal precipitation (Figure $5 \mathrm{E}-\mathrm{G}$ ). 

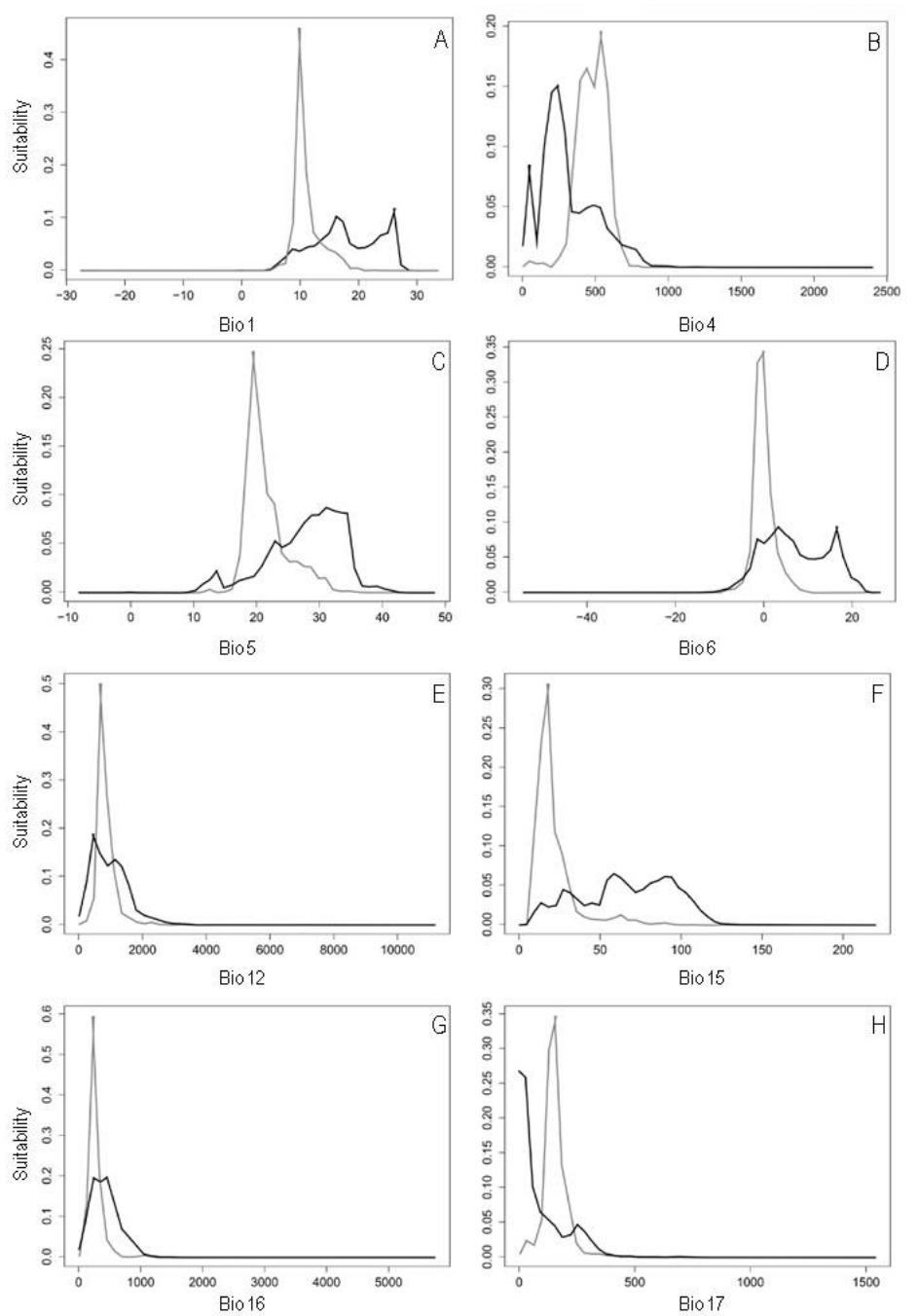

Figure 5. Predicted niche occupancy (PNO) profiles. The vertical axes show the total suitability of the bioclimatic variable and the horizontal axes show the bioclimatic variable for each range over its geographic distribution. The overlapping zones indicate similar climatic tolerances, and the amplitude of the profile indicates the specificity of climatic tolerance. Black lines represent the native range of Azolla filiculoides, and grey lines the invasive range of Azolla filiculoides. (A) Annual mean temperature (Bio 1), (B) temperature seasonality (Bio 4), (C) maximum temperature of the warmest month (Bio 5), (D) minimum temperature of the coldest month (Bio 6), (E) annual precipitation (Bio 12), (F) precipitation seasonality (Bio 15), (G) precipitation of the wettest quarter (Bio 16), and (H) precipitation of the driest quarter (Bio 17).

\subsection{Potential Distribution Comparisons Under Future Scenarios}

When the models were considered under future emission scenarios, a dramatic reduction in the potential distribution of $A$. filiculoides, especially in the native area, was observed (Figure 6 and Figure S3). This reduction was more pronounced under the pessimistic emission scenario (RCP 8.5; Figure S3). The overlap of global circulation models (GCMs) was high, especially under the optimistic emission scenario (RCP 4.5; Figure S4). In contrast, under the pessimistic emission scenario (RCP 8.5), and mainly for the later temporal period (2080), the models showed greater variability in terms of predicted projections (Figures S3 and S4). Additionally, according to the models, A. filiculoides becomes displaced towards the poles in the invaded areas (Figure 6 and Figure S3). Of particular importance is the increasing suitability towards eastern and northern Europe, where the species is currently unknown 
or exceedingly rare but could colonize and spread to further climatically suitable areas (Figure 6 and Figure S3).
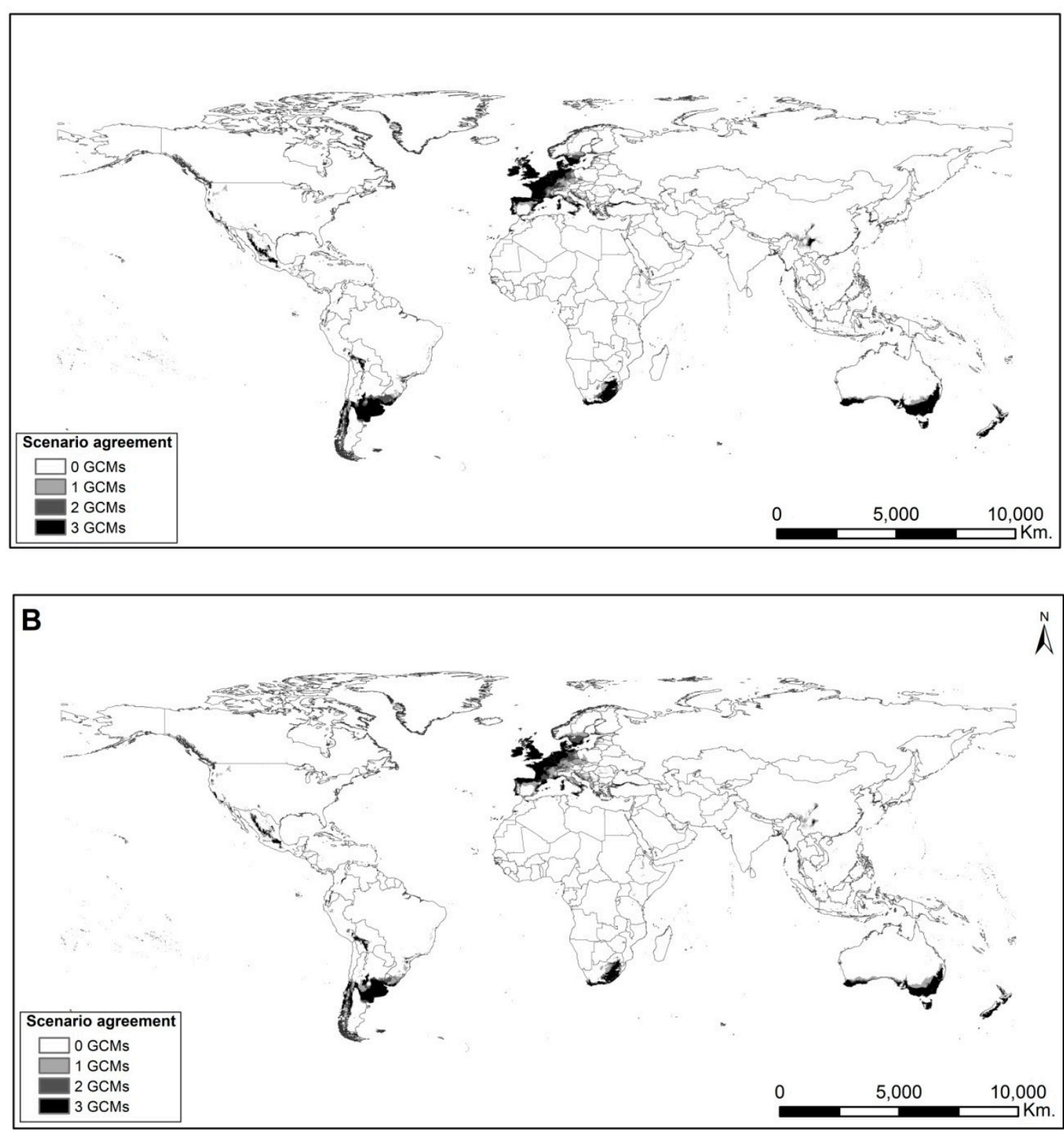

Figure 6. Projected potential distribution of Azolla filiculoides under the optimistic emission scenario (RCP 4.5) and three different GCMs. (A) 2050. (B) 2080. Darker shades indicate greater overlapping of GCMs.

\section{Discussion}

Our findings demonstrate that the climatic niche of $A$. filiculoides in both ranges, native and invaded, is similar but not identical. According to the identity test results, niche overlap was less than expected by the null model. Therefore, the identity null hypothesis was rejected, suggesting that native and invaded niches are environmentally different [31]. On the other hand, the background similarity test results indicated that the niches are more similar than expected by chance and, thus, the null hypothesis of background similarity could not be rejected [31]. Taken together, our results indicate that $A$. filiculoides shares environmental niche spaces in both distribution ranges, presenting similar climatic requirements. However, different environmental variables restrict its potential distribution in 
the two areas, and new suitable environments appear to be available for $A$. filiculoides in the invaded range, suggesting an environmental niche shift between native and invaded areas.

Several factors can induce a niche shift during the invasion process, which, in turn, can facilitate colonization of an area with novel combinations of environmental conditions, leading a species to exceed the limits of its native niche and to occupy different non-native niches [33]. These factors include abiotic differences, biotic interactions, dispersive barriers or human activities [11]. Climatic differences can play an important role in ecological divergence processes [34,35] by, promoting the adaptation of species to new climatic environments [36]. Our models support the cosmopolitan distribution of $A$. filiculoides and, as demonstrated by the PNO profiles, indicate that the species is able to survive in a wide spectrum of environmental conditions. In addition, the low niche conservatism of $A$. filiculoides makes it a very dangerous invaders of freshwater ecosystems as, it is able to survive in a wide variety of habitats, including extreme climatic environments, such as in Great Britain, where the species survives in very low temperatures compared to those of its native range [22].

The effect of human activity also significantly influences the invasion processes of non-native species [37]. Indeed, Rodríguez-Merino et al. [38,39] previously described how the human footprint (a variable that represents the impact of humans on a territory) is a key variable in the potential distribution of A. filiculoides. In this context, changes in watersheds by human activities (e.g.,: agricultural, industrial) can affect aquatic species distribution [40], causing habitat loss for native species and, consequently, the occupation of empty habitats by non-native species (empty niche hypothesis [41]). Additionally, the access to available resources is one of the major drivers controlling the invasion process (fluctuating resources theory [42]). Another important aspect to consider is role of potential competitors that can regulate non-native species populations by, limiting their dispersion in the invaded range (enemy release hypothesis [41]). The absence/presence of competitors and predators changes the environmental conditions of an invaded area [11]. This has been demonstrated for A. filiculoides in the invaded range: the species is in decline or has disappeared at sites in which its natural enemy, the weevil Stenopelmus rufinasus, is found [43]. For example, in Doñana, $A$. filiculoides has disappeared from ponds with $S$. rufinasus but thrives in nearby water bodies uninhabited by the weevil. The influence of these factors together with highly successful clonal growth [26] and the symbiosis with its cyanobiont [25], could imply changes in the $A$. filiculoides invasive niche during the invasion process.

The models under future projections suggest that $A$. filiculoides could colonize new areas outside its native range where it is still absent. In this context, there is a large proportion of aquatic environments susceptible to being colonized by the species. Changes in the future potential distribution of $A$. filiculoides were more pronounced under higher emission concentration (pessimistic) scenario (RCP 8.5), particularly in Europe where the species distribution is projected to have a northward latitudinal trend. However, the effects of climate change will not only influence the species' geographic trends (latitudinal and/or altitudinal) but also its potential distribution area, which will be reduced. These results coincide with those proposed for other AIS in Europe [4]. From the perspective of $A$. filiculoides invasion management and control, the reduction of its non-native potential distribution area is good news. However, the effects of climate change will also transform aquatic ecosystem conditions, which will, in turn, influence the distribution of native aquatic vegetation through the potential loss of available habitats and consequent loss of populations [44]. In addition, $A$. filiculoides shows an alarming reduction of potential distribution in its native area, caused by the loss of suitable habitats in some regions, a trend that is observed for other AIS [4].

Increasing water temperatures and water regime alterations caused by changes in precipitation could cause displacements in the species distribution areas, including the non-native area [3]. In the case of $A$. filiculoides, increasing temperatures and, consequently, environmental aridification could lead to the loss of available habitats. However, new area gains towards high latitudes, particularly in northern Europe, have been detected, as our analyses suggest. This demonstrates that new habitats are available for A. filiculoides. On the other hand, the decrease and change in rainfall frequency could influence aspects related to connectivity and the dispersion of the species towards new environments [4]. 
Our results indicate that niche equivalence analyses provide crucial information for SDM projections, allowing the potential distribution of non-native species to be more accurately assessed. Similar results have been proposed for other AIS [19]. The high AUC values showed that the reciprocal models performed very well, although they are not adequate to determine the species potential distribution onto the projected range, especially when the transfer is from the invaded onto the native area. In this context, the combination of species occurrence data (native and invaded localities) can substantially improve the accuracy of the potential distribution prediction [11]. However, the use of these methods is not sufficient to detect whether the change produced in the species environmental niche between native and invaded ranges is caused by a truly adaptive process, by a change in propagule pressure success or even by historical contingency process [9]. Regarding this, it would be interesting to perform future studies related to the physiological aspects of $A$. filiculoides, to assess its adaptive capacity in the face of different stress factors in order to determine which are the main drivers that explain the niche shift during the invasion process.

\section{Materials and Methods}

\subsection{Occurrence Records}

An A. filiculoides occurrence records database was compiled from three sources: Global Biodiversity Information Facility (GBIF, http://www.gbif.org/; https://doi.org/10.15468/dl.wph41n), Species Link (http://splink.cria.org.br/) and TROPICOS (http://www.tropicos.org/). Occurrence records from native area were checked using standard floras (Supplementary Materials, Annex S1). To minimize overfitting due to the potential negative effect of spatial autocorrelation [45], the occurrence records were limited to one per pixel of environmental layers.

\subsection{Bioclimatic Variables}

Bioclimatic variables used for building the models were previously described by Fick and Hijmans [46] and were obtained from the WorldClim database (Table S1, http://www.worldclim.org/ version2), at 5 -arc minute spatial resolution ( 10 km at the Equator). The bioclimatic variables describe the average, the variation (seasonality) and the extreme values of temperature and precipitation. These variables induce physiological stress in plants and are useful to limit the distribution of aquatic plants [47]. The number of environmental variables used to fit models was reduced to minimize model overfitting [48]. Eight variables were selected: annual mean temperature (Bio 1), temperature seasonality (Bio 4), maximum temperature of the warmest month (Bio 5), minimum temperature of the coldest month (Bio 6), annual precipitation (Bio 12), precipitation seasonality (Bio 15), precipitation of the wettest quarter (Bio 16) and precipitation of the driest quarter (Bio 17). These bioclimatic variables have been shown to be useful for studying the potential distribution of aquatic plants at large scales and for establishing the potential geographic limits of species and the climatic variability to which aquatic plants are exposed $[4,47,49]$. To obtain the best possible models, we did not eliminate correlated variables as the maximum entropy algorithm (see species distribution modeling section) makes robust predictions even when variables are correlated $[50,51]$. This capacity allows the algorithm to choose the most explanatory variables among all variables included in the species distribution modeling [50,52].

The future potential distribution of $A$. filiculoides was projected for two future emission scenarios, one optimistic and the other pessimistic, using the representative concentration pathways (RCPs: 4.5 and 8.5, respectively) [53], and for two time periods (2050 and 2080) using three global circulation models (GCMs): CSIRO MK 3_6_0, MIROC MIROC 5 and MOHC HADGEM 2 ES. The use of three GCMs accounts for the uncertainty associated with such models [54]. These data were obtained from the CGIAR Research Program on Climate Change, Agriculture and Food Security (http://www.ccafs-climate.org). 


\subsection{Niche Overlap in Environmental Space}

Principal Component Analysis (PCA) was used to quantify differences between native and invaded niches in multidimensional environmental space. The A. filiculoides occurrence records were plotted against eight selected bioclimatic variables to obtain a two-dimensional climatic range summarized by the first two axes of the PCA [12]. PCA analyses were run using the 'ggfortify' package [55] and the data were visualized using the 'ggplot2' package [56] implemented in R software v3.1.2 [57].

\subsection{Species Distribution Modeling}

Species distribution models (SDMs) were used to establish the geographic pattern of $A$. filiculoides and to compare environmental niche differences between native and invaded areas. SDMs were run under the maximum entropy model implemented in the MaxEnt software v.3.3.3k [58]. The MaxEnt model has proven to perform better than other modeling methods and is one of the most effective presence-only data algorithms currently available [59-62]. MaxEnt models were generated by default parameters ('Auto features', convergence $=10^{-5}$, maximum number of iterations $=500$, prevalence $=0.5$, regularization value $\beta=1$ ) $[50,59,63]$. The MaxEnt algorithm requires the use of background points: these are random points that represent the calibration area, which typify the environmental conditions available for the species [50]. Three background datasets of 10,000 points each were generated: (a) in the global model, the points were selected from all suitable lands except Antarctica, the only area where A. filiculoides does not grow; (b) in the native model (see reciprocal niche models section), the points were selected from throughout the Americas; and (c) in the invasive model, they were selected from all areas where A. filiculoides grow, excluding the Americas and Antarctica. Ten replicates were run for each model to estimate the associated error with the fitted function using $70 \%$ of the presence to train the model, and the remaining 30\% to test the model [50]. The area under the receiver operating characteristic (ROC) curve, or AUC value, was used to evaluate model accuracy. The AUC is the most popular metric to evaluate MaxEnt models [51]. Continuous suitability maps were transformed into binary maps (presence/absence) using the 10th percentile training presence threshold [39,64].

\subsection{Reciprocal Niche Models}

Geographical niche shifts during the invasion process were studied by reciprocal models. A model with only native occurrences was first run and then projected onto the invasive area (native model). A second model with only invaded occurrences was then run and projected onto the native area (invasive model). A final model run was with both native and invasive occurrences (global model) $[12,65]$.

\subsection{Niche Overlap Analyses}

To estimate niche overlap, Schoener's $D$ and a modified Hellinger distance's I statistics were calculated using the 'phyloclim' package implemented in R [66]. The values of the two metrics range from 0 (no niche overlap) to 1 (total niche overlap). The classification proposed by Rödder and Engler [67] was followed to facilitate the interpretation of the degree niche overlap. These measures were used to test niche identity (or niche equivalence) and background similarity between native and invaded ranges in the geographical space [31]. The niche identity test determines whether the niches observed in both geographic ranges (native and invaded) are more equivalent than expected by chance when the occurrences of both distributions (native and invasive) are reassigned between the two analyzed ranges. The background similarity test determines whether the overlap between occupied niches can be attributed to the available environmental space [68]. These metrics are commonly used to compare geographical models [69]. For both tests, 100 randomizations were performed to produce the null distributions [31]. 


\subsection{Predicted Niche Occupancy}

Predicted niche occupancy (PNO) profiles quantify the multimodal variation in bioclimatic parameters through species probability distribution obtained by the SDMs [70]. The PNO profiles were used to estimate the climatic tolerances of $A$. filiculoides, in its native and invasive ranges [36]. The PNO analyses were built in the 'phyloclim' package implemented in R [66], using MaxEnt raw outputs and 50 equally spaced bins spanning the parameter range of each bioclimatic variable [71].

\subsection{Potential Distribution Comparisons Under Future Scenarios}

To address the effects of climate change on the future potential distribution of $A$. filiculoides, global binary models were used to quantify the predicted suitable area. Three binary maps corresponding to three GCMs were stacked for each climatic emission scenario (RCPs: 4.5 and 8.5) and for each studied time period (2050 and 2080) in order to quantify potential distribution coincidences between GCMs.

\section{Conclusions}

The prevention and the control of biological invasions are crucial aspects to consider for the maintenance of ecosystemic stability, particularly given that invasive species can negatively impact ecosystems [33]. Our results provide useful insights to anticipate the presence of $A$. filiculoides in areas of high invasion risk, on the basis of its bioclimatic requirements, as well as to establish conservation strategies for the species in its native area. We consider our approach for determining possible divergences in both distribution ranges very useful for non-native aquatic plants, since they can alter their physiology in response to novel conditions in the invaded range due to their high plasticity, which could allow future species niche evolution [9]. Considering this, the use of species occurrence records in the native and invaded ranges allows us to develop more precise geographic models that include the environmental variability acquired by the species in newly colonized ranges. Taken together, this information can serve as a powerful resource to help decision makers establish early warning systems to mitigate the effects of future invasions of $A$. filiculoides under climate change pressures. In addition, this protocol can be applied to other invasive species in different ecosystems.

Supplementary Materials: The following are available online at http://www.mdpi.com/2223-7747/8/10/424/s1, Annex S1: References list of traditional floras to establish the native area of Azolla filiculoides, Table S1: Description of bioclimatic variables according to WorldClim available at http://www.worldclim.org/version2, Figure S1: The graphs show the niche identity test, showing Schoener's $D$ and modified Hellinger distance's $I$. The observed similarity between niches is indicated with the line, while bars indicate the null distribution of ecological niche distances generated randomly. Shoener's $D$ and Hellinger distance's I range from 0 (completely different), to 1 (identical), Figure S2: The graphs show the background similarity test, showing Schoener's $D$ and modified Hellinger distance's $I$. The observed similarity between niches is indicated with the line, while bars indicate the null distribution of ecological niche distances generated randomly. Shoener's $D$ and Hellinger distance's I range from 0 (completely different), to 1 (identical), Figure S3: Projected potential distribution of Azolla filiculoides under the pessimistic emission scenario (RCP 8.5), corresponding to three different GCMs. (A) 2050. (B) 2080. Darker shades indicate greater overlapping of GCMs, Figure S4: Number of total pixels (1 pixel 10km of resolution) predicted as suitable under each GCM projection. The data corresponds to the sum of the binary models. Overlap values: 1 GCM (no model overlap), 2 GCMs (two models overlap) and 3 GCMs (three models overlap).

Author Contributions: Conceptualization, A.R.-M., R.F.-Z., P.G.-M. and J.M.; methodology, A.R.-M. and J.M.; investigation, A.R.-M. and J.M.; data curation, A.R.-M.; formal analysis, A.R.-M. and J.M.; visualization, A.R.-M.; writing-original draft preparation, A.R.-M.; writing-review and editing, A.R.-M., R.F.-Z., P.G.-M. and J.M.; supervision, R.F.-Z., P.G.-M. and J.M.

Funding: This research received no external funding.

Acknowledgments: We thank Sergio Ortega and Vladimir Sandoval for their comments about the first findings of this work. We are indebted to our Royal Botanical Garden of Madrid library colleagues, for their patience and availability in the search of data in American's Floras.

Conflicts of Interest: The authors declare no conflict of interest. 


\section{References}

1. Sala, O.E.; Chapin, F.S.; Armesto, J.J.; Berlow, E.; Bloomfield, J.; Dirzo, R.; Huber-Sanwald, E.; Huenneke, L.F.; Jackson, R.B.; Leemans, R.; et al. Global biodiversity scenarios for the year 2100. Science 2000, 287, 1770-1774. [CrossRef]

2. Collen, B.; Whitton, F.; Dyer, E.E.; Baillie, J.E.M.; Cumberlidge, N.; Darwall, W.R.T.; Pollock, C.; Richman, N.I.; Soulsby, A.-M.; Böhm, M. Global patterns of freshwater species diversity, threat and endemism. Glob. Ecol. Biogeogr. 2014, 23, 40-51. [CrossRef]

3. Bellard, C.; Thuiller, W.; Leroy, B.; Genovesi, P.; Bakkenes, M.; Courchamp, F. Will climate change promote future invasions? Glob. Chang. Biol. 2013, 19, 3740-3748. [CrossRef]

4. Gillard, M.; Thiébaut, G.; Deleu, C.; Leroy, B. Present and future distribution of three aquatic plants taxa across the world: Decrease in native and increase in invasive ranges. Biol. Invasions 2017, 19, 2159-2170. [CrossRef]

5. Broennimann, O.; Treier, U.A.; Müller-Schärer, H.; Thuiller, W.; Peterson, A.T.; Guisan, A. Evidence of climatic niche shift during biological invasion. Ecol. Lett. 2007, 10, 701-709. [CrossRef]

6. Zanden, M.J.V.; Olden, J.D. A management framework for preventing the secondary spread of aquatic invasive species. Can. J. Fish. Aquat. Sci. 2008, 65, 1512-1522. [CrossRef]

7. Barnes, M.A.; Jerde, C.L.; Wittmann, M.E.; Chadderton, W.L.; Ding, J.; Zhang, J.; Purcell, M.; Budhathoki, M.; Lodge, D.M. Geographic selection bias of occurrence data influences transferability of invasive Hydrilla verticillata distribution models. Ecol. Evol. 2014, 4, 2584-2593. [CrossRef]

8. Petitpierre, B.; Kueffer, C.; Broennimann, O.; Randin, C.; Daehler, C.; Guisan, A. Climatic niche shifts are rare among terrestrial plant invaders. Science 2012, 335, 1344-1348. [CrossRef]

9. Guisan, A.; Petitpierre, B.; Broennimann, O.; Daehler, C.; Kueffer, C. Unifying niche shift studies: Insights from biological invasions. Trends Ecol. Evol. 2014, 29, 260-269. [CrossRef]

10. Tingley, R.; Vallinoto, M.; Sequeira, F.; Kearney, M.R. Realized niche shift during a global biological invasion. Proc. Natl. Acad. Sci. USA 2014, 111, 10233-10238. [CrossRef]

11. Wan, J.-Z.; Wang, C.-J.; Tan, J.-F.; Yu, F.-H. Climatic niche divergence and habitat suitability of eight alien invasive weeds in China under climate change. Ecol. Evol. 2017, 7, 1541-1552. [CrossRef]

12. Medley, K.A. Niche shifts during the global invasion of the Asian tiger mosquito, Aedes albopictus Skuse (Culicidae), revealed by reciprocal distribution models. Glob. Ecol. Biogeogr. 2010, 19, 122-133. [CrossRef]

13. Peterson, A.T. Predicting the geography of species' invasions via ecological niche modeling. Q. Rev. Biol. 2003, 78, 419-433. [CrossRef]

14. Thuiller, W.; Richardson, D.M.; Pyšek, P.; Midgley, G.F.; Hughes, G.O.; Rouget, M. Niche-based modelling as a tool for predicting the risk of alien plant invasions at a global scale. Glob. Chang. Biol. 2005, 11, 2234-2250. [CrossRef]

15. Gallien, L.; Münkemüller, T.; Albert, C.H.; Boulangeat, I.; Thuiller, W. Predicting potential distributions of invasive species: Where to go from here? Divers. Distrib. 2010, 16, 331-342. [CrossRef]

16. Guisan, A.; Thuiller, W. Predicting species distribution: Offering more than simple habitat models. Ecol. Lett. 2005, 8, 993-1009. [CrossRef]

17. Gallardo, B.; Clavero, M.; Sánchez, M.I.; Vilà, M. Global ecological impacts of invasive species in aquatic ecosystems. Glob. Chang. Biol. 2015, 22, 151-163. [CrossRef]

18. Santamaría, L. Why are most aquatic plants widely distributed? Dispersal, clonal growth and small-scale heterogeneity in a stressful environment. Acta Oecol. 2002, 23, 137-154. [CrossRef]

19. Wang, C.-J.; Wan, J.-Z.; Qu, H.; Zhang, Z.-X. Climatic niche shift of aquatic plant invaders between native and invasive ranges: A test using 10 species across different biomes on a global scale. Knowl. Manag. Aquat. Ecosyst. 2017. [CrossRef]

20. Svenson, H.K. The new world species of Azolla. Am. Fern J. 1944, 34, 69-84. [CrossRef]

21. Hussner, A. NOBANIS-Invasive Alien Species Fact Sheet-Azolla filiculoides. Online Database of the European Network on Invasive Alien Species. 2010. Available online: hppt://www.nobanis.org (accessed on 16 October 2019).

22. Janes, R. Growth and survival of Azolla filiculoides in Britain I. Vegetative production. New Phytol. 1998, 138, 367-375. [CrossRef] 
23. Janes, R.A.; Eaton, J.W.; Hardwick, K. The effects of floating mats of Azolla filiculoides Lam. and Lemna minuta Kunth on the growth of submerged macrophytes. In Management and Ecology of Freshwater Plants; Caffrey, J.M., Barrett, P.R.F., Murphy, K.J., Wade, P.M., Eds.; Springer: Dordrecht, The Netherlands, 1996; pp. 23-26.

24. Carrapiço, F. Azolla as a Superorganism. Its implication in symbiotic studies. In Symbioses and Stress: Joint Ventures in Biology; Seckbach, J., Grube, M., Eds.; Springer: Dordrecht, The Netherlands, 2010; pp. 225-241. ISBN 978-90-481-9449-0.

25. De Vries, S.; de Vries, J. Azolla: A model system for symbiotic nitrogen fixation and evolutionary developmental biology. In Current Advances in Fern Research; Fernández, H., Ed.; Springer International Publishing: Cham, Switzerland, 2018; pp. 21-46. ISBN 978-3-319-75103-0.

26. Fernández-Zamudio, R.; Cirujano, S.; Sánchez-Carrillo, S.; Meco, A.; García-Murillo, P. Clonal reproduction of Azolla filiculoides Lam.: Implications for invasiveness. Limnetica 2013, 32, 245-252.

27. McConnachie, A.J.; Hill, M.P.; Byrne, M.J. Field assessment of a frond-feeding weevil, a successful biological control agent of red waterfern, Azolla filiculoides, in southern Africa. Biol. Control 2004, 29, 326-331. [CrossRef]

28. Sheppard, A.W.; Shaw, R.H.; Sforza, R. Top 20 environmental weeds for classical biological control in Europe: A review of opportunities, regulations and other barriers to adoption. Weed Res. 2006, 46, 93-117. [CrossRef]

29. García-Murillo, P.; Fernández-Zamudio, R.; Cirujano, S.; Sousa, A.; Espinar, J.M. The invasion of Doñana National Park (SW Spain) by the mosquito fern (Azolla filiculoides Lam). Limnetica 2007, 26, 243-250.

30. Champion, P.D.; Clayton, J.S.; Hofstra, D.E. Nipping aquatic plant invasions in the bud: Weed risk assessment and the trade. Hydrobiologia 2010, 656, 167-172. [CrossRef]

31. Warren, D.L.; Glor, R.E.; Turelli, M. Environmental niche equivalency versus conservatism: Quantitative approaches to niche evolution. Evolution 2008, 62, 2868-2883. [CrossRef] [PubMed]

32. Warren, D.L.; Glor, R.E.; Turelli, M. ENMTools: A toolbox for comparative studies of environmental niche models. Ecography 2010, 33, 607-611. [CrossRef]

33. Nunes, A.L.; Tricarico, E.; Panov, V.E.; Cardoso, A.C.; Katsanevakis, S. Pathways and gateways of freshwater invasions in Europe. Aquat. Invasions 2015, 10, 359-370. [CrossRef]

34. Graham, C.H.; Ron, S.R.; Santos, J.C.; Schneider, C.J.; Moritz, C.; Cunningham, C. Integrating phylogenetics and environmental niche models to explore speciation mechanisms in dendrobatid frogs. Evolution 2004, 58, 1781-1793. [CrossRef]

35. Rissler, L.J.; Apodaca, J.J.; Weins, J. Adding more ecology into species delimitation: Ecological niche models and phylogeography help define cryptic species in the black salamander (Aneides flavipunctatus). Syst. Biol. 2007, 56, 924-942. [CrossRef] [PubMed]

36. Gamisch, A.; Fischer, G.A.; Comes, H.P. Frequent but asymmetric niche shifts in Bulbophyllum orchids support environmental and climatic instability in Madagascar over Quaternary time scales. BMC Evol. Biol. 2016, 16, 14. [CrossRef] [PubMed]

37. Gallardo, B.; Zieritz, A.; Aldridge, D.C. The importance of the human footprint in shaping the global distribution of terrestrial, freshwater and marine invaders. PLOS ONE 2015, 10, e0125801. [CrossRef] [PubMed]

38. Rodríguez-Merino, A.; Fernández-Zamudio, R.; García-Murillo, P. An invasion risk map for non-native aquatic macrophytes of the Iberian Peninsula. In Anales del Jardín Botánico de Madrid; Consejo Superior de Investigaciones Científicas: Madrid, Spain, 2017; Volume 74, pp. 1-10.

39. Rodríguez-Merino, A.; García-Murillo, P.; Cirujano, S.; Fernández-Zamudio, R. Predicting the risk of aquatic plant invasions in Europe: How climatic factors and anthropogenic activity influence potential species distributions. J. Nat. Conserv. 2018, 45, 58-71. [CrossRef]

40. Abell, R.; Allan, J.D.; Lehner, B. Unlocking the potential of protected areas for freshwaters. Biol. Conserv. 2007, 134, 48-63. [CrossRef]

41. Jeschke, J.M. General hypotheses in invasion ecology. Divers. Distrib. 2014, 20, 1229-1234. [CrossRef]

42. Davis, M.A.; Grime, J.P.; Thompson, K. Fluctuating resources in plant communities: A general theory of invasibility. J. Ecol. 2001, 88, 528-534. [CrossRef]

43. Florencio, M.; Fernández-Zamudio, R.; Bilton, D.T.; Díaz-Paniagua, C. The exotic weevil Stenopelmus rufinasus Gyllenhal, 1835 (Coleoptera: Curculionidae) across a "host-free" pond network. Limnetica 2015, 34, 79-84. 
44. Porter, E.M.; Bowman, W.D.; Clark, C.M.; Compton, J.E.; Pardo, L.H.; Soong, J.L. Interactive effects of anthropogenic nitrogen enrichment and climate change on terrestrial and aquatic biodiversity. Biogeochemistry 2013, 114, 93-120. [CrossRef]

45. Boria, R.A.; Olson, L.E.; Goodman, S.M.; Anderson, R.P. Spatial filtering to reduce sampling bias can improve the performance of ecological niche models. Ecol. Model. 2014, 275, 73-77. [CrossRef]

46. Fick, S.E.; Hijmans, R.J. WorldClim 2: New 1-km spatial resolution climate surfaces for global land areas. Int. J. Climatol. 2017, 37, 4302-4315. [CrossRef]

47. Kelly, R.; Leach, K.; Cameron, A.; Maggs, C.A.; Reid, N. Combining global climate and regional landscape models to improve prediction of invasion risk. Divers. Distrib. 2014, 20, 884-894. [CrossRef]

48. Heikkinen, R.K.; Luoto, M.; Araújo, M.B.; Virkkala, R.; Thuiller, W.; Sykes, M.T. Methods and uncertainties in bioclimatic envelope modelling under climate change. Prog. Phys. Geogr. 2006, 30, 751-777. [CrossRef]

49. Rodríguez-Merino, A.; Fernández-Zamudio, R.; García-Murillo, P. Identifying areas of aquatic plant richness in a Mediterranean hot spot to improve the conservation of freshwater ecosystems. Aquat. Conserv. Mar. Freshw. Ecosyst. 2019, 29, 589-602. [CrossRef]

50. Elith, J.; Phillips, S.J.; Hastie, T.; Dudík, M.; Chee, Y.E.; Yates, C.J. A statistical explanation of MaxEnt for ecologists. Divers. Distrib. 2011, 17, 43-57. [CrossRef]

51. Merow, C.; Smith, M.J.; Silander, J.A. A practical guide to MaxEnt for modeling species' distributions: What it does, and why inputs and settings matter. Ecography 2013, 36, 1058-1069. [CrossRef]

52. Velásquez-Tibatá, J.; Salaman, P.; Graham, C.H. Effects of climate change on species distribution, community structure, and conservation of birds in protected areas in Colombia. Reg. Environ. Chang. 2013, 13, 235-248.

53. IPCC Working Group I. IPCC Fifth Assessment Report (AR5)—The Physical Science Basis; Cambridge University Press: Cambridge, UK; New York, NY, USA, 2013.

54. Buisson, L.; Thuiller, W.; Casajus, N.; Lek, S.; Grenouillet, G. Uncertainty in ensemble forecasting of species distribution. Glob. Chang. Biol. 2010, 16, 1145-1157. [CrossRef]

55. Tang, Y.; Horikoshi, M.; Li, W. ggfortify: Unified interface to visualize statistical results of popular R packages. $R$ J. 2016, 8, 474-485. [CrossRef]

56. Wickham, H. ggplot2: Elegant Graphics for Data Analysis; Springer: New York, NY, USA, 2009; ISBN 978-0-387-98141-3.

57. R Core Development Team. R: A Language and Environment for Statistical Computing; R Foundation for Statistical Computing: Viena, Austria, 2016; Available online: http://www.R-project.org (accessed on 16 October 2019).

58. Phillips, S.J.; Anderson, R.P.; Schapire, R.E. Maximum entropy modeling of species geographic distributions. Ecol. Model. 2006, 190, 231-259. [CrossRef]

59. Elith, J.; Graham, C.H.; Anderson, R.P.; Dudík, M.; Ferrier, S.; Guisan, A.; Hijmans, R.J.; Huettmann, F.; Leathwick, J.R.; Lehmann, A.; et al. Novel methods improve prediction of species' distributions from occurrence data. Ecography 2006, 29, 129-151. [CrossRef]

60. Wisz, M.S.; Hijmans, R.J.; Li, J.; Peterson, A.T.; Graham, C.H.; Guisan, A.; NCEAS Predicting Species Distributions Working Group. Effects of sample size on the performance of species distribution models. Divers. Distrib. 2008, 14, 763-773. [CrossRef]

61. Elith, J.; Leathwick, J.R. Species distribution models: Ecological explanation and prediction across space and time. Annu. Rev. Ecol. Evol. Syst. 2009, 40, 677-697. [CrossRef]

62. Mateo, R.G.; Croat, T.B.; Felicísimo, Á.M.; Muñoz, J. Profile or group discriminative techniques? Generating reliable species distribution models using pseudo-absences and target-group absences from natural history collections. Divers. Distrib. 2010, 16, 84-94. [CrossRef]

63. Phillips, S.J.; Dudík, M. Modeling of species distributions with Maxent: New extensions and a comprehensive evaluation. Ecography 2008, 31, 161-175. [CrossRef]

64. Liu, C.; Berry, P.M.; Dawson, T.P.; Pearson, R.G. Selecting thresholds of occurrence in the prediction of species distributions. Ecography 2005, 28, 385-393. [CrossRef]

65. Fitzpatrick, M.C.; Weltzin, J.F.; Sanders, N.J.; Dunn, R.R. The biogeography of prediction error: Why does the introduced range of the fire ant over-predict its native range? Glob. Ecol. Biogeogr. 2007, 16, 24-33. [CrossRef]

66. Heibl, C.; Calenge, C. Phyloclim: Integrating Phylogenetics and Climatic Niche Modeling; Version 0.9.4. 2014. Available online: http://cran.r-project.org/web/packages/phyloclim/ (accessed on 1 June 2018). 
67. Rödder, D.; Engler, J.O. Quantitative metrics of overlaps in Grinnellian niches: Advances and possible drawbacks. Glob. Ecol. Biogeogr. 2011, 20, 915-927. [CrossRef]

68. Broennimann, O.; Fitzpatrick, M.C.; Pearman, P.B.; Petitpierre, B.; Pellissier, L.; Yoccoz, N.G.; Thuiller, W.; Fortin, M.-J.; Randin, C.; Zimmermann, N.E.; et al. Measuring ecological niche overlap from occurrence and spatial environmental data. Glob. Ecol. Biogeogr. 2012, 21, 481-497. [CrossRef]

69. Meng, L.; Chen, G.; Li, Z.; Yang, Y.; Wang, Z.; Wang, L. Refugial isolation and range expansions drive the genetic structure of Oxyria sinensis (Polygonaceae) in the Himalaya-Hengduan Mountains. Sci. Rep. 2015, 5, 10396. [CrossRef]

70. Evans, M.E.K.; Smith, S.A.; Flynn, R.S.; Donoghue, M.J. Climate, niche evolution, and diversification of the "bird-cage" evening primroses (Oenothera, sections Anogra and Kleinia). Am. Nat. 2009, 173, 225-240. [CrossRef] [PubMed]

71. Nyári, Á.S.; Reddy, S. Comparative phyloclimatic analysis and evolution of ecological niches in the scimitar babblers (Aves: Timaliidae: Pomatorhinus). PLoS ONE 2013, 8, e55629. [CrossRef] [PubMed]

(C) 2019 by the authors. Licensee MDPI, Basel, Switzerland. This article is an open access article distributed under the terms and conditions of the Creative Commons Attribution (CC BY) license (http://creativecommons.org/licenses/by/4.0/). 